\title{
VIVENCIANDO COM O FILHO UMA PASSAGEM DIFÍCIL E REVELADORA - A EXPERIÊNCIA DA MÃE ACOMPANHANTE*
}

\section{EXPERIENCING A DIFFICULT AND REVEALING PASSAGE WITH HER CHILD - THE LIVE-IN MOTHER EXPERIENCE}

\author{
Irma de Oliveira** \\ Margareth Angelo***
}

OLIVEIRA, I; ANGELO,M. Vivenciando com o filho uma passagem dificil e reveladora - a experiência da mãe acompanhante.

Rev.Esc.Enf.USP, v. 34, n. 2, p. 202-8, jun. 2000.

\section{RESUMO}

O presente estudo foi realizado com mães acompanhantes em um hospital escola. Os objetivos foram: compreender as interações vivenciadas, identificar os significados que o familiar acompanhante atribui à experiência de vivenciar a hospitalização da criança, identificar o que essa vivência provoca na vida do familiar e construir um modelo teórico representativo da experiência. Utilizou-se como Referencial Teórico o Interacionismo Simbólico e Referencial Metodológico a "Grounded Theory". Identificou-se os fenômenos Indo em busca de solução e Atravessando uma situação difícil. A partir desses fenômenos emergiu a categoria central Vivenciando com o filho uma passagem difícil e reveladora.

PALAVRAS-CHAVE: Mãe acompanhando filho no hospital. Família

\begin{abstract}
This study was conducted with live-in mother in university hospital. The objectives were as follows: to understand the experienced interactions, to identify the meanings that a family attribute to the experience of going through the child's hospitalization, to identify what the experience of hospitalization provokes in the family life and construct a model theory representative of the experience. Reference Theory the Symbolic Interactionism and Reference Methodology Grounded Theory had been utilized. From results appeared the phenomenon Going in search of solution, and Going through a difficult situation. Through these phenomena, the main category Experiencing a difficult and revealing passage with her child was identified.
\end{abstract}

KEYWORDS: Mother with child in hospital. Family.

\section{CONSIDERAÇÕES INICIAIS}

A permanência da família no hospital participando dos cuidados junto a criança internada é defendida há muito tempo e tem suscitado muitos estudos.

A maioria desses trabalhos mostra o que a criança sente quando é hospitalizada e o que este evento desencadeia no seu crescimento e desenvolvimento emocional, bem como os sentimentos que os pais, mais especificamente as mães, manifestam(D'ANDREA, 1962; ESCARDÓ;
GILBERTI, 1963; LISBOA. 1973; HARDGROVE; RUTLEDGE, 1975; GUTIERREZ，1980; BIERMAN, 1980; NUNES, 1981; NEIRA HUERTA, 1984; CYPRIANO; FISBERG, 1990, GONÇALVES, 1992).

A hospitalização da criança é um evento que altera toda a dinâmica da família, em razão dos vínculos de estreita relação que caracterizam a relação criança-família (SMITHERMAN, 1979; SANTOS, 1984; HENSE, 1991).

\footnotetext{
* Trabalho baseado na Tese de Doutorado: Vivenciando com o filho uma passagem dificil e reveladora - a experiência da mãe acompanhante, defendida em 1998.

** Enfermeira. Professora Assistente Doutor do Departamento de Enfermagem da Faculdade de Ciências Médicas da Universidade Estadual de Campinas - Unicamp. E-mail: denffcm@fcm.unicamp.br***

Enfermeira. Professor Doutor do Departamento de Enfermagem Materno Infantil e Psiquiátrica da Escola de Enfermagem da Universidade de São Paulo - USP.
} 
A esse respeito, NUGENT et al. (1992) acrescentam que a doença da criança, com ou sem internação, constitui uma crise, não só para ela, mas também para a família como um todo. Desequilíbrios são produzidos por eventos circunstanciais que afetam não só os membros mas o funcionamento da unidade. Como a família percebe esse evento depende da sua habilidade de manejar recursos e de um sistema de apoio para ela. Ao que MACEDO (1994) e JERRET (1994) complementam que ao longo de suas vidas, as famílias vivenciam problemas e enfrentam situações críticas, mas cada uma apresenta as suas peculiaridades e seus padrões interacionais específicos; por isso, a experiência da doença é considerada no contexto de significados que ela tem para a família.

É nesse contexto que a criança e seus problemas de saúde devem ser considerados. A doença em si pode desencadear uma crise na vida da criança e da família. A interpretação da doença depende das percepções, do suporte disponivel e das habilidades de que a família dispõe no momento para enfrentar esse episódio (SANTOS, 1982; SCHIMITZ et al., 1989; ELSEN; PATRICIO, 1989).

AMICO; DAVIDHIZAR (1994) asseguram que a tensão, os medos, as fantasias e a pressão emocional causados pela doença da criança afetam não só os pais, mas também todos os membros da família. Outras crianças sentem a pressão e a tensão criadas pela doença. Freqüentemente, quando uma criança está criticamente doente, ocorre um desarranjo no conjunto da unidade familiar. A estrutura da família e os padrões usuais de funcionamento são significativamente alterados e a familia precisa descobrir uma forma de manejar a situação.

Defendendo a importância de se considerar a família como o foco de cuidado, LADEBAUCHE (1992) afirma que o foco da enfermagem pediátrica tem mudado gradualmente do cuidado da criança para o cuidado centrado na família. Avaliar o impacto psicossocial da hospitalização sobre a criança tem sido integrado na prática clínica em muitos hospitais que provêem assistência à criança, embora as avaliações de família como um todo e o impacto da hospitalização em cada um dos membros sejam colocados em segundo plano.

DARBYSHIRE (1994) afirma que as questões relacionadas aos pais acompanhantes e o cuidado centrado na família são mais desafiantes do que se supunha. Ele enfatiza a necessidade de os profissionais compreenderem as experiências reais vividas pelo familiar acompanhante quando seus filhos estão hospitalizados.

ANGELO (1997) nos diz que a definição de enfermagem tradicionalmente considera o indivíduo e sua família como objeto da sua intervenção. No entanto, a prática e a história revelam que, na verdade, o foco da atenção da enfermagem foi o indivíduo, na maioria das vezes, cabendo à família uma localização mais à margem dos acontecimentos. Embora a família fosse considerada como parte da experiência do indivíduo, ela raramente era acessada e valorizada no processo de cuidar. Ainda hoje é tida como um recurso em beneficio do indivíduo, mas não como um objeto de atenção da enfermagem.

No que diz respeito a conceituação de família, ELSEN (1994) assinala que a opção por um conceito de família a partir de um referencial se constitui em uma decisão dificil em razão de exigir uma definição do profissional quanto a sua visão de mundo, de Enfermagem, de ambiente e de família, com seus conhecimentos, crenças valores adquiridos ao longo da sua vida. Daí a necessidade de escolher um referencial coerente com o seu próprio posicionamento frente à vida, à saúde e à profissão.

ANGELO (1997), compreendendo a família segundo a perspectiva do Interacionismo Simbólico, define "como um grupo de indivíduos (atores), chegando às situações com outros significantes ou grupos de referência, com símbolos, perspectivas, self, mente e habilidade para assumir papéis. Cada ator tem um passado a resgatar para ajudar a definir a situação e cada um tem uma visão de futuro. Os atores dão significado às situações usando estes instrumentos, às vezes prestando especial atenção àqueles com quem interagem na situação, outras vezes usando algo localizado fora da situação como guia".

Concordamos com essa autora e entendemos também que, para cuidar da família, temos que percebê-la inteira, numa dimensão que extrapola as suas experiências exteriorizadas. Cuidar de família exige fundamentalmente a captação das suas experiências internas, aquelas que nos revelam os significados que a família atribui aos eventos que vivencia.

Assim, nesse estudo, buscamos nos aproximar do mundo do familiar acompanhante na vivência da hospitalização da criança para:

- compreender como se dão as interações vivenciadas pelo familiar acompanhante;

- identificar os significados que o familiar acompanhante atribui à experiência de vivenciar a hospitalização.

- identificar o que a vivência da hospitalização da criança provoca na vida do familiar acompanhante.

Construir um modelo teórico sobre a experiência do familiar acompanhante que vivencia a hospitalização da criança. 


\section{FUNDAMENTAÇÃO TEÓRICA- , METODOLÓGICA}

Os referenciais Interacionismo Simbólico (IS) e Teoria Fundamentada nos Dados (TFD) que direcionam este estudo, obedecem ao nosso propósito de utilizar abordagens teóricometodológicas que permitam apreender e desenvolver conceitos explicativos dos significados da experiência vivenciada pelo familiar acompanhante.

O IS busca compreender a natureza das interações humanas. A particularidade de o ser humano interagir, interpretar, definir e agir no seu cotidiano de acordo com o significado que ele atribui à situação vivenciada.

Segundo BLUMMER (1969), a natureza do IS se fundamenta em três premissas básicas:

- Os seres humanos agem em relação às coisas com base no significado que elas têm para eles.

- Os significados das coisas é derivado da interação social que o ser humano estabelece com outras pessoas. O IS vê os significados como produtos sociais definidos na interação.

- Os significados são manipulados e modificados através de um processo interpretativo, que o ser h humano estabelece ao lidar com as coisas e com a situação em que ele se encontra.

A TFD permite a geração de teorias a partir de dados coletados e analisados de maneira sistemática e simultânea através de um método comparativo constante. O número de sujeitos a serem estudados é determinado pela amostragem teórica, processo de coleta de dados para gerar teoria. O pesquisador coleta, codifica, analisa os dados e decide quais outros vai coletar, a fim de desenvolver a teoria que está emergindo. A coleta de dados é efetuada até a repetição e ausência de dados novos, e a densificação das categorias desenvolvidas ou seja-, até; acontecer a saturação teórica (GLASER; STRAUSS, 1967; ANGELO, 1997).

\section{DESCRIÇÃO DA PESQUISA}

O estudo foi realizado em uma unidade de internação pediátrica de um hospital escola de um município do interior do Estado de São Paulo. Essa unidade, desde 1986, adota o sistema de alojamento conjunto, mas cabe à família, no momento da internação, a decisão de ficar ou não com a criança, bem como de escolher o elemento da família que será o acompanhante.

Os dados foram coletados através da observação participante e entrevistas no período de abril de 1996 a agosto de 1997. A partir das observações pudemos perceber a mãe se configurando como o acompanhante da criança; por conta disso, o nosso foco de atenção passou a ser a mãe acompanhante. Foram estudadas 18 mães acompanhantes distribuídas em 5 grupos amostrais: o primeiro foi constituído de 7 mães que estavam acompanhando o filho há mais de uma semana e vivenciavam a experiência pela primeira vez; o segundo grupo amostral de 6 mães que eram acompanhantes há mais de 10 dias, tinham outros filhos e não trabalhavam fora; o terceiro de 2 mães que vivenciavam a hospitalização há mais de 10 dias e trabalhavam fora; o quarto grupo de 2 mães que foram surpreendidas pela hospitalização em razão dos filhos serem submetidos a cirurgias de emergências e o quinto e último grupo por 1 mãe que vivenciara inúmeras hospitalizações com a mesma criança.

A coleta e análise dos dados foi acontecendo ao longo do estudo de maneira concomitante conforme preconiza a TFD. Os dados foram organizados, analisados linha por linha, parágrafo por parágrafo, cada dado sublinhado e codificado. Após a codificação inicial, os dados foram comparados e agrupados um a um por suas similaridades, formando as categorias, que por sua vez, foram comparadas entre si, reorganizadas em agrupamentos, reduzidas, transformando-se em categorias abrangentes, com suas subcategorias e seus componentes.

Essas categorias realinhadas e comparadas evidenciaram as categorias mais densas e essas selecionadas revelaram os aspectos mais significativos da vivência, a categoria central e a construção do modelo teórico representativo do processo vivenciado pela mãe na sua experiência de acompanhante.

\section{APRESENTANDO OS RESULTADOS}

A comparação e a análise dos dados permitiram compreender que a experiência que a mãe vivencia na trajetória de acompanhante em um hospitalescola não se limita apenas à fase em que ela permanece no hospital junto do filho, mas também a uma etapa anterior, caracterizada pelo movimento que a mãe empreende na tentativa de resolver o problema da criança.

O fenômeno INDO EM BUSCA DE SOLUÇÃO revela essa experiência inicial. A mãe é a primeira pessoa a perceber que o filho não está bem e a tentar descobrir o que está ocorrendo. Ela faz de tudo. Uma vez não conseguindo resolver o problema em família, parte à procura de ajuda profissional. Na medida em que o problema continua e ela 
percebe o filho piorando, mais preocupada toma outras providências, ou seja, parte em busca de outros recursos até encontrar uma solução para um problema cuja responsabilidade ela acredita competir a ela.

Essa busca incessante culmina com a internação da criança e a mãe internando-se com ela para vivenciar a árdua trajetória de acompanhante do filho hospitalizado conforme evidencia $\mathrm{o}$ fenômeno ATRAVESSANDO UMA SITUAÇÃO DIFÍCIL.

A mãe enfrenta tudo para cumprir o que define como sendo o seu dever de mãe. Ela se entrega à missão prioritária de proteger, de poupar o filho de mais sofrimento, afastando-se dos outros filhos, da sua família, de outros deveres. A mãe sofre junto com o filho, vivencia a dor de não poder fazer nada para impedir o sofrimento dele, e de não se sentir reconhecida por alguns profissionais no cumprimento de sua obrigação de mãe.

A vivência desses fenômenos é revelada nas categorias que os compõem.

Convivendo com a dor e o sofrimento. Acompanhando o filho hospitalizado, a mãe é exposta a uma vastidão de eventos que que promovem medo, angústia e insegurança. Ela sofre por não saber o que pode acontecer ao filho, pelas incertezas quanto a doença e ao tratamento, e por temer a possibilidade de alguma coisa dar errado e ela perder o seu filho. A mãe sofre assistindo ao sofrimento, sofre junto com o filho e sofre pelo fato de vê-lo sofrendo, em especial nas situações em que ele é submetido aos procedimentos terapêuticos dolorosos na sua frente, sem que ela possa fazer alguma coisa para evitar ou minimizar a dor dele. A mãe também vivencia a dor de sentir-se impotente, de ser incapaz de livrar o seu filho do sofrimento.

"Ah!, para mim parecia que era o fim do mundo, porque a gente fica com medo, eu pensava logo assim: Deixar ela no hospital, eu tinha muito medo..." $(\boldsymbol{K}, 60)$

"Eu fiquei foi nervosa, pensava besteira, olhava ela (criança) daquele jeito sem querer saber de nada, pensei em tudo, em coisas sérias a gente escuta falar tanta coisa..." (Pe, 3)

"Toda vez que tem de pegar a veia eu já penso Meu Deus é muito triste para uma mãe ver o filho passar por uma coisa dessa, eu já sei que ela vai sofrer min'(1),149)
"É muito triste ver o filho da gente desse jeito: sofrendo com dor e a gente não poder fazer nada, dói lá no fundo." $(0,2)$

Não se entregando. Em meio a tanto sofrimento a mãe não se rende, luta com determinação, rompendo barreira por barreira. Apoiada na fé, na profunda ligação que ela estabelece com Deus, encara as suas dificuldades e ajuda as outras acompanhantes a enfrentarem as suas. Tomada de esperança ela não se permite desanimar, vai em frente acreditando que tudo vai ser resolvido.

"A gente sempre tem uma esperança que ela se livre dessa dor." (R, 391).

"Eu pedia muita força para Deus, que Deus me ajudasse, nossa (dá um sorriso), se Deus quiser nós vamos embora (dá mais um sorriso)..." (SL, 99)

Dando proteção ao filho. A mãe realiza ações para conseguir proporcionar conforto físico e emocional ao filho, ao mesmo tempo em que se mantém vigilante controlando tudo o que é ou não é feito com a criança. Ela observa, realiza procedimentos, pede explicações, dá informações, ajuda, se capacita para cuidar e não deixar passar nada que possa desencadear mais sofrimento ao filho.

\section{"Estou sempre procurando não deixar ele triste, eu faço de tudo pra ele." (T, 45) \\ "Eu acho que tem de estar em cima e prestar muita atenção, porque eu acho que um remédio errado pode dar um problemao." (C, 1250)}

Tendo ajuda. Embora seja uma vivência solitária na linha de frente, a mãe recebe algum tipo de ajuda que contribui para sua força, fundamental para que ela vivencie o seu papel de acompanhante. Ela se sente ajudada quando conta com o apoio e solidariedade das pessoas que estão preocupadas com a criança e com ela, ou seja, familiares, amigos e alguns profissionais.

\section{"Eles ficaram todos do meu lado: Calma, se Deus quiser, vai dar certo. Só pedia para mim ter calma que ia dar certo..." (Sl, 2) \\ "Minha tia fica com outro filho meu, cuida, faz tudo..." (Ce, 29)}

Vivendo momentos de insegurança. Ao longo de sua trajetória de acompanhante, a mãe se depara com situações que a deixam apreensiva. Uma delas acontece quando ela percebe o filho sendo cuidado por profissionais que ela julga inábeis e ineptos e a outra quando ocorre mudança dos profissionais que vinham realizando com sucesso o tratamento da criança.. 
"... Agora, você quer ver eu ficar num desespero é eu estar falando que o menino não está bem, e a enfermeira não estar nem aí." (Cr, 147)'

"... Eu pensei: Puxa vida! Eu acho que ela está em profissão errada, porque eu acho que desde à hora que você aceita ser enfermeira (auxiliar de enfermagem) você tem que aceitar tudo, né, você tem, porque é o que eu falo, eu não sirvo, você entende?" (Cr, 169)

Sentindo-se muito exigida. Em alguns momentos na sua vivência de acompanhante, a mãe sente-se não dando conta de responder a todos os papéis que ela define como seus. Ela se descobre querendo cumprir com seus deveres para com o filho hospitalizado e com os demais elementos da família. Em função disso, ela se sente dividida, pressionada, sobrecarregada, não conseguindo se desligar e no limite de suas forças.

"Meu pensamento está aqui, e se eu estou aqui, meu pensamento está lá; então eu fico assim indecisa, às vezes, eu nem sei direito o que eu faço. Fico muito indecisa..." (Ce, 36)

"Ela (profissional) falou para mim: Aî, mãe, você tem que manter a calma, tem que ser forte, você tem que dar força para ele. Então você fica nervosa, é lógico..." (Cr, 6)

"Esses dias eu estou fazendo um esforço para aguentar, né; nem dormir a gente anda dormindo, porque você fica cansada né, você fica estressada e assim vai indo..." (Ro, 123)

Tendo a vida revirada. A condição de mãe acompanhante desencadeia uma reviravolta na vida da família. Ao se internar junto com o filho, a mãe tem que assumir responsabilidades que lhe exigem muita dedicação e sacrifício. Em função disso, ela muda seus hábitos e a sua relação com a família é transformada.

"De uma hora para outra, mudou o meu ritmo de vida, tive que deixar tudo para ficar aqui." $(0,171)$

Sentindo-se recompensada. Ao perceber que o problema da criança se encaminha à resolução, a mãe observa que seus esforços não foram em vão. Confiante, ela sente que está perto de conseguir o seu intento, ou seja, ver a criança livre da doença e longe do hospital após enfrentar tantas dificuldades.

"Eu achei um alivio, eu achei o problema, né." (J, 318)"Acabou o problema, acabou o mistério, já encontrei a solução." (N, 231)
Tendo que viver outras internações. A medida que as internações se repetem, mãe e criança vão ficando cada vez mais fragilizadas. A mãe por testemunhar o sofrimento da criança e por pensar que, em uma dessas crises, ela pode perder o seu filho. É uma fase em que a mãe sente a necessidade de ter mais apoio para lidar melhor com o sofrimento que ela tem de enfrentar.

"Porque aqui eu sei que se acontecer alguma coisa, eles têm o que fazer. Eu falei: Para eu vir da minha casa aqui, eu sei que eu posso chegar e não ter condição de fazer mais nada..." (Cr, 402)

"Deu trabalho para convencer ele. Ele chorava desesperado, desesperado, sabe. Ele pegou medo de hospital, pânico de hospital... Eu conversava bastante com ele, fui ajudando, ele parou de chorá, conseguimos pôr ele dentro do carro e trouxemos embora (para internar)." (T, 424)

Dando outro sentido à vida. A vivência do sofrimento dá a mãe acompanhante a oportunidade de descobrir e refletir sobre o lado dificil e doloroso da vida. Aprendendo lições sobre a vida enquanto enfrenta o sofrimento e compartilha do sofrimento de outras pessoas, a mãe passa a lidar com a vida de outra maneira.

"Eu aprendi bastante, viu, e aprendi que não é fácil lidar com a vida, porque, às vezes, a gente está bem e de uma hora pra outra a gente está mal." (Ce, 59)

"Sabe, eu acho assim, me fez abrir os olhos né, ao mesmo tempo que a gente sofre, passa a dar mais valor para as pessoas do seu lado..." (Cr, 141)

"Aprendi aceitar as coisas. Eu era super nervosa não podia nem ver gente doente $e$ agora eu estou aprendendo aceitar as coisas. Eu não estou mais apavorada, com aquele medo ..." (T, 75)

"Você vê o sofrimento, você vai aprendendo, vai vendo, vai enxergando..." $(R, 145)$

\section{DESCOBRINDO A CATEGORIA CENTRAL}

A descoberta da categoria central não foi nada simples. Compreender o significado da experiência da mãe que vivencia a hospitalização 
exigiu muito, uma vez que a questão não era tão somente interpretar os dados. Era interpretar, sim, mas também transcender aquilo que se mostrava evidente e apreender o que estava "velado" para reconhecer a categoria central, ou seja, aquela predominante, capaz de representar a essência da experiência.

O processo da sua busca se deu através de uma comparação e análise dos fenômenos Indo em Busca de Solução e Atravessando uma Situação Difícil para compreender como se dava a interação entre os seus componentes, e encontrar as categorias-chave, que, agrupadas e analisadas, permitiram a identificação do fenômeno, da categoria central VIVENCIANDO COM O FILHO UMA PASSAGEM DIFÍCIL E REVELADORA, definida dessa maneira pelo fato de ela ser abrangente, e integrar-se a outras categorias e revelar o significado da experiência da mãe acompanhante.

A análise dos dados mostra que a vivência da mãe é marcada por desafios e revelações. Em linguagem simbólica, a mãe acompanhante experimenta e transpõe as dificuldades, ao mesmo tempo em que descobre sobre a vida e ela na vida.

O enfrentamento desta situação tem início no momento em que a mãe se percebe Tendo que Internar-se com o Filho, uma decisão que ela toma movida pela sua responsabilidade de prover o melhor para a criança. Assumindo esse papel, ela empreende uma luta para vencer a dificuldade que é conviver com a dor sem se render a ela.

O sofrimento é inerente à condição da mãe acompanhante. Ele vai assumindo contornos diferentes ao longo da sua experiência, tornando-se mais ou menos intenso consoante os significados que ela atribui à doença, ao tratamento e o que isso provoca em sua vida. Consciente do seu papel, a mãe enfrenta o sofrimento com a determinação de proteger o filho, de minimizar a sua dor, uma vez que ela não tem como livrá-lo do sofrimento.

A mãe sabe que o filho precisa dela. Por essa razão, assume encarar o sofrimento, Não se Entregando. O sofrimento e a decisão de não se entregar a ele acontecem de maneira simultânea, o que quer dizer que, se de um lado a mãe sofre, por outro lado, ela não se rende.

Convivendo com a dor e o sofrimento, a mãe tem de aceitar a sua impotência frente a uma vastidão de eventos que desencadeiam o processo de sofrer, tão presente na vivência de ser mãe acompanhante da criança hospitalizada. Ela enfrenta a dificuldade de ter que experimentar um grande sofrimento, sofrer com o filho, com o seu próprio sofrimento e, mesmo assim, manter-se firme pára poder garantir o melhor para a criança.
Assim, à medida que a mãe vai passando por esse processo, ela vai definindo e redefinindo a sua linha de enfrentamento. Pode-se dizer que, impelida pelo dever moral de cuidar do filho, ela faz de tudo pela criança. Dando Proteção representa 0 conjunto de ações que a mãe realiza com o filho, com o propósito de amenizar o seu sofrimento.

A mãe acredita que tem de estar ao lado do filho passando tudo junto com ele. Por isso, ela se coloca na linha de frente, buscando manter as suas emoções sob controle, fazendo tudo para defendê-lo de mais sofrimento.

Dessa forma, o Não se Entregando determina suas ações e mobiliza suas forças para suportar as dificuldades. Mesmo Sentindo-se Muito Exigida, não desiste, não se entrega, não se permite deixar levar pelo desânimo ou pelos pensamentos negativos. Ancorada na sua fé, busca ajuda em um Ser Superior, renova as suas forças, as suas esperanças e persevera no seu dever de proteger o filho.

Sofrendo e, ao mesmo tempo, se empenhando para não se entregar, a mãe vai Dando Outro Sentido a Sua Vida. Independentemente de conseguir resolver o problema do seu filho ou não, a sua relação com a vida vai sendo transformada.

O embate com o sofrimento possibilita à mãe pensar e enxergar a vida de uma outra maneira, uma vez que ela não vivencia o sofrimento pelo sofrimento. Não, ela aprende a perceber o outro e a desenvolver-se como ser humano. Movimentando-se entre a fragilidade e a fortaleza humana, ela passa a se sentir diferente. O sofrimento dá a oportunidade de ela olhar para dentro de si, refletir e re-orientar as suas ações na vida. .

Dessa forma, a categoria central, VIVENCIANDO COM O FILHO UMA PASSAGEM DIFÍCIL E REVELADORA, define a experiência da mãe e representa a compreensão do sofrido processo que ela vivencia na sua trajetória de acompanhante.

\section{CONSIDERAÇÕES FINAIS}

O jeito interacionista de pensar a mãe acompanhante nos permite conhecer parte de seu mundo interno e a TFD descobrir o lado velado da sua experiência, aquele que nós, profissionais, temos dificuldades de perceber e valorizar.

Enxergar a mãe acompanhante através do IS é apreender o seu mundo de significados sob a sua perspectiva, é criar situações interacionais que propiciem a ela agir, refletir e redirecionar as sua ações e, assim, a sua própria transformação. É considerar a interação não somente como uma causa dos comportamentos mas, também, como base para a sua experiência. 
Assim, a captação desse processo interacionista é que permite ao profissional compreender o que a mãe está passando, o que ela está sentindo, o que ela está precisando. Nesse sentido, o modelo teórico VIVENCIANDO COM O FILHO UMA PASSAGEM DIFÍCIL E REVELADORA conforme preconiza a TFD não está fechado, concluído, o que significa dizer: esta proposição teórica é dinâmica e por isso poderá ser ampliada a partir do momento que outros dados forem acrescentados à compreensão dessa realidade.

Dessa forma, este modelo teórico é um instrumento que capacita, dá poder para o enfermeiro mudar ou justificar a sua maneira de agir com a mãe acompanhante. No entanto, ele não encerra toda a possibilidade da experiência do acompanhante, porque este papel pode ser vivenciado por outros elementos da família; e nós não sabemos quais definições essas pessoas têm dessa vivência.

Acreditamos que mais estudos precisam ser realizados para que possamos apreender o significado dessa experiência para outros familiares acompanhantes e assim, podermos transformar a nossa prática de enfermagem com a família.

\section{REFERÊNCIAS BIBLIOGRÁFICAS}

AMICO, J; DAVIDHIZAR, R. Supporting families of critically ill chidren. J.Clin.Nurs., v. 3, n. 4, p. 213-8, 1994.

ANGELO, M. Com a familia em tempos difíceis: uma perspectiva de enfermagem. São Paulo, 1997. 118 p. Tese (Livre Docência) - Escola de Enfermagem, Universidade de São Paulo.

BIERMAN, G. A criança e a hospitalização. Documento Roche. n. 3, p. 83-90, 1980.

BLUMER, H. Simbolic interactionism: perspective and method. Englewood Cliffs, Prentice-Hall, 1969.

CYPRIANO, M. S.; FISBERG, M. Mãe-participante - benefícios e barreiras. J.Ped., v. 66, n. 4/5, p. 92-7, 1990.

D'ANDREA, F. F. Aspectos psicológicos da hospitalização infantil. Rev. Bras. Enf., v.15, n. 5, p. 417-23, 1962.

DARBYSHIRE, P. Living with a sick child in hospital. the experiences of parents and nurses. London, Chapman \& Hall, 1994. cap. 3, p. 55-82: The moral imperative: being a "good parent", cap. 4, p. 83-119: Parental involvement and participation.

ELSEN, I. Desafios da enfermagem no cuidado de famílias. In: BUB, L. I. R. et al. Marcos para a prática de enfermagem com familias. Florianópolis, UFSC, 1994. cap. 2, p. 61-78.

ELSEN, I.; PATRÍCIO, Z. M. A assistência à criança hospitalizada. tipos de abordagens, suas implicações para a enfermagem. In: SCHMITZ, E. M. et al. A enfermagem em pediatria e puericultura. Rio de Janeiro, Atheneu, 1989. cap. 15, p. 169-79.
ESCARDO, F.; GILBERTI, E. Sobre hospitalismo. Rev. Colomb. Ped. Pueric., v. 20, n. 3, p. 157-73, 1963.

GLASER, B. G.; STRAUSS, A. L. The discovery of grounded theory strategies for qualitative research. New York, Aldine de Guyter, 1967.

GONCCALVES, R. C. et al. Hospitalização conjunta mãe e filho no Hospital das Clínicas da Universidade Estadual de Campinas: avaliação de um grupo de mães. Rev. Paul. Enf., v. 11, n. 3, p. 111-5, 1992

GUTIÉRREZ, G. La participatión de la família en la proteción y recuperación de la salud del nino in los hospitals de pediatria. Bol. Med. Hosp. Méx., v. 37, n. 4, p. 563-5, 1980.

HARDGROVE, C.; RUTLEDGE, A. Parenting during hospitalization. Am. J. Nurs., v. 75, n. 5, p. 836-8, 1975.

HENSE, D. et al. Assistindo à criança hospitalizada no sistema de internação conjunta: percepções e abordagens de uma equipe de enfermagem. Florianópolis, 1991. / mimeografado/.

JERRET, M. D. Parent's experience of coming to know the care of a chronically ill child. J. Adv. Nurs., v. 19, n. 6, p. 1050-6, 1994.

LADEBAUCHE, P. A reminder. MCN. v. 17, n. 1, p. 18-21, 1992.

LISBOA, A. M. J. Programa de hospitalização conjunta mãe-filho. J. Ped., v. 38, n. 7/8, p. 191-4, 1973.

MACEDO, R. M. A familia do ponto de vista psicológico: lugar seguro para crescer? Cad. Pesq., n. 91, p. 62-8, 1994.

NEIRA HUERTA, E. del. P. A experiência de acompanhar um filho hospitalizado - sentimentos, necessidades e expectativas manifestadas por mães acompanhantes. São Paulo, 1984. 145p. Dissertação (Mestrado) - Escola de Enfermagem, Universidade de São Paulo.

NUGENT, K. et al. A practice model for a parent support group. Ped. Nurs., v. 18, n. 1, p. 11-6, 1992.

NUNES, D. M. Alojamento conjunto pediátrico. Rev. Gaúcha Enf., v. 3, n. 1, p. 41-50, 1981.

SANTOS, M. E. R. et al. A hospitalização da criança: a visão do familiar. J. Ped., v. 56, n. 6, p. 391-5, 1984.

SANTOS, M. L. C. Problemática da criança hospitalizada e a extensão à comunidade. Rev. Esc. Enf. USP, v. 16, n. 1, p. $107-11,1982$.

SCHMITZ, E. M. et al. A enfermagem em pediatria e puericultura. Rio de Janeiro, Atheneu, 1989. cap. 16, p. 181-96: A problemática da hospitalização infantil: aspectos psicológicos.

SMITHERMAN, C. H. Parents of hospitalized children have needs, too. Am. J. Nurs., v. 79, n. 8, p. 1423-4, 1979. 